\title{
Índice Craneano en Grupos Étnicos Precolombinos del Norte de Chile con Deformación Craneal Artificial
}

\author{
Cranial Index in Precolumbian Ethnic Groups of Northern Chile \\ with Artificial Cranial Deformation
}

*Fernando García-Hernández \& ** Gabriel Murphy-Echeverría

GARCÍA-HERNÁNDEZ, F \& MURPHY-ECHEVERRÍA, G. Índice craneano en grupos étnicos precolombinos del Norte de Chile con deformación craneal artificial. Int. J. Morphol., 27(2):587-594, 2009.

RESUMEN: Durante el período precolombino, en el norte de Chile habitaron diversos grupos humanos, con notorias diferencias etnoculturales. Una de sus características fue la deformación craneana artificial usando vendas y tablas durante los primeros años de vida, existiendo dos grandes modelos de deformación: tabular que producía braquicefalia y anular o circular que determinaba dolicocefalia. La investigación pretende demostrar la relación existente entre hábitat, tipo de deformación artificial y forma de la cabeza determinada por el índice craneano. Se estudiaron 77 cráneos atacameños de ambos sexos, seleccionados al azar de entre 293 individuos exhumados del cementerio Coyo-Oriente, datados entre 300-1200 d.C. período post-Tiwanaku y que forman parte del Museo R.P. Gustavo Le Paige en San Pedro de Atacama, dependiente del Instituto de Investigaciones Arqueológicas de la Universidad Católica del Norte y siete cráneos aymaras con deformación craneana artificial pertenecientes al museo anatómico de la Universidad de Antofagasta. Todos los cráneos fueron analizados, fotografiados y mensurados para determinar el índice craneano. Se comprobó que un 35,1\% de los cráneos atacameños estaban deformados artificialmente, predominando la deformación tabular (92,6\%), los cráneos deformados presentan un promedio de índice craneano de 92,63 SD 9,72, y con el 100\% de los casos con braquicefalia. Los siete cráneos aymaras estaban deformados en forma artificial mediante el método circular o anular, con un promedio de índice craneano de 76,0\% SD 6,66 y con un 42,8\% de los casos dolicocéfalos. El análisis estadístico estableció diferencias significativas al 95\% del índice craneano entre atacameños con cráneos deformados y aymaras, y además, entre índices craneanos de atacameños con y sin cráneos deformados. En el norte de Chile, los cráneos deformados artificialmente pueden adoptar formas braquicéfalas o dolicocéfalas sin aparente predominio a causa de territorio, época cultura.

PALABRAS CLAVE: Índice craneano; Deformación craneana; Norte de Chile.

\section{INTRODUCCIÓN}

Desde tiempos inmemorables los seres humanos han modificado sus características corporales con propósitos culturales o sociales (Torres-Rouff, 2007). Las modificaciones $\mathrm{y}$ adornos corporales son un potente medio para transmitir información sobre su pertenencia grupal, entre las cuales destacan las modificaciones corporales permanentes como la deformación craneana artificial (Meskell, 1998; TorresRouff, 2007).

La deformación craneana puede ser provocada por causas naturales (de tipo congénita o por sinostosis temprana) o por métodos artificiales que tienen un patrón etnocultural. La deformación craneana artificial se conoce desde tiempos antiguos, siendo practicada por diversos gru- pos étnicos en casi todas las civilizaciones, culturas o regiones, tales como Egipto, Asia Menor, en áreas de Europa que estaban bajo el control del Imperio Romano y en los territorios actuales de Hungría, Alemania e Inglaterra, entre otros. Sin embargo, la mayor frecuencia y variación se encuentra en el continente americano, en los grupos indoamericanos mohave de norteamérica, de la actual Colombia, Imperio Maya, Imperio Inca, Tiwanaku y diversas otras culturas andinas (Boada, 1995; Torres-Rouff \& Yablonsky, 2005; Borja Villanueva \& Gálvez Calla, 2006). Gracias a esta gran variedad existente en América, Imbelloni desarrolló la clasificación y descripción más sistémica de las diversas variables de deformación artificial (citado por Comas, 1976).

\footnotetext{
* Unidad de Anatomía, Departamento Biomédico, Facultad de Ciencias de la Salud, Universidad de Antofagasta, Chile.

** Cirujano Dentista
} 
El propósito de la deformación craneana artificial varía de acuerdo a la cultura y a la región. Mientras en ciertas regiones es un símbolo de nobleza o permite separar diversos grupos dentro de la sociedad, en otras sirve para resaltar diferencias étnicas o fue realizada por estética, magia o razones religiosas (Shijman, 2005). Las deformaciones craneanas descritas en grupos reducidos y dispersos pueden deberse más a decisiones familiares, por parentesco, ayllu o etnia más que a prácticas controladas por el estado gobernante (Torres-Rouff, 2007).

La deformación artificial del cráneo es una práctica cultural que modela la cabeza infantil para obtener una forma adulta característica, describiéndose en las culturas originarias del norte de Chile todos los diferentes tipos de deformación descritos (Rothhammer \& Llop, 2004).

Estos diferentes tipos de deformación craneana se agrupan en dos categorías principales (Fig. 1), según el método empleado (Björk \& Björk, 1964; Comas; Torres-Rouff, 2003):

- Deformación tipo tabular, mediante la aplicación de almohadillas o tablas rígidas que aplanan las partes frontal y occipital del cráneo provocando una expansión de la anchura craneal (braquicefalización).

- Deformación tipo anular o circular, llamada también "Aymara" por la zona de influencia de Tiwanaku (Imbelloni en 1924; Latchman en 1937 y Marroquín en 1944, todos citados por Torres-Rouff, 2007), que aplica vendas alrededor del cráneo produciendo una deformación tubular y alargada hacia atrás, disminuyendo el ancho y aumentando la longitud anteroposterior del cráneo (dolicocefalización).

En ambos tipos se describen las variantes erecta y oblicua, que se definen por la angulación posterior del cráneo (Torres-Rouff, 2007).

La forma de la bóveda craneana se determina por visión en norma superior de la cabeza, clasificando a los individuos en dos grandes grupos: braquicéfalos (predominio de la anchura) y dolicocéfalos (predominio de la longitud). Pese a lo anterior, una forma más objetiva para determinar la forma de la bóveda craneal es usar el índice craneano en cráneos secos, llamado índice cefálico cuando se determina la forma craneal en individuos vivos. Se emplea la fórmula matemática que multiplica el ancho interparietal máximo por 100, dividiendo el producto por la longitud anteroposterior máxima del cráneo medida entre la glabela y el opistocráneo.

Este índice craneano permite clasificar la forma de la bóveda craneal en norma superior en: Hiperbraquicéfalos igual o más de 85,0; Braquicéfalos entre 80,0 y 84,9; Mesocéfalos entre 75,0 y 79,9; Dolicocéfalos entre 70,0 y 74,9 e Hiperdolicocéfalos igual o menos de 69,9 (clasificación de Martin, citado por Morel, 1964)

En los grupos humanos ha ido en aumento la braquicefalización de la cabeza, principalmente en los xantodermos (etnia amarilla), siendo menor este rasgo en los caucásicos y melanodermos (etnia negra) donde existe mayor grado de dolicocefalia y de acuerdo a la Ley de Pitard, los grupos de individuos con menor estatura tienden a presentar braquicefalia (del Sol, 2005)

Según Henri Vallois (citado por Valls, 1985) los habitantes del norte de Chile pertenecen a la subetnia surpacífica o neoamerindia. En dicha población amerindia predomina la braquicefalia, rasgo o característica que se observaría desde el período formativo hasta ser predominante a la llegada de los europeos (Valls en 1980, citado por Martí \& Rothhammer, 1987).

Nuestra investigación se ceñirá a dos grupos étnicos del norte de Chile: atacameños que representan actualmente el 3\% de la población originaria del país y aymaras que corresponden al 7\% de la población amerindia de Chile (Bustos, 1999; Bustos \& Lehnert, 2000). En primer lugar, el grupo atacameño corresponde a individuos que habitaban en las cercanías del oasis de San Pedro de Atacama, importante centro caravanero para las diferentes poblaciones del altiplano andino. Según Torres-Rouff (2007) no existió en San Pedro de Atacama una forma organizada de controlar la forma de la cabeza de su población, predominando la deformación tabular.

La expansión del estado altiplánico de Tiwanaku desde los Andes centrales del sur influye en las regiones vecinas (Torres-Rouff \& Yablonsky) y en especial en San Pedro de Atacama a partir del año 600 d.C. (Berenguer \& Dauelsberg en 1986, citador por Torres-Rouff, 2007). Después del año 1000 d.C. con la penetración de diversos grupos altiplánicos aparece una mayor presencia de formas circulares de deformación que se consideran relacionados con el centro lejano de Tiwanaku, que concedió prestigio y autoridad a ciertos individuos (Helms, 1992 citado por TorresRouff, 2007; Knudson, 2007).

Numerosos investigadores plantean la existencia de dos grupos culturales diferentes viviendo en forma paralela en el desierto de Atacama (Castro et al., 1984; Aldunate et al., 1986; Museo del Arte Pre-Colombino, 1988; Schiapacasse et al., 1989). En oposición a lo anterior, estudios realizados por Knudson usando isótopos del estroncio no identificó individuos enterrados en cementerios de San 
Pedro de Atacama que hubiesen vivido durante sus primeros años de vida en el sector sur del lago Titicaca, provenientes del Estado de Tiwanaku o de sus descendientes, entre los cuales predominaba la deformación craneana artificial de tipo anular o circular, por lo que se considera como más plausible que los habitantes de San Pedro de Atacama fueran influenciados comercial y culturalmente por Tiwanaku, incluyendo como forma ritual el tipo de deformación craneal circular, más que por una cohabitación o colonización Tiwanacota.

El segundo grupo en estudio corresponde al pueblo aymara, que se considera descendiente de los antiguos habitantes de Tiwanaku, que ocupaban un hábitat en el norte de Chile que se extendía entre los valles de Azapa y Quillagua, formaban parte de la cultura Arica, la cual fue absorbida por la expansión del Imperio Inca en el siglo XV. Como ya se señaló en párrafos anteriores, entre los tiwanacotas predominaba la deformación de tipo circular o anular, sin embargo trabajos recientes han concluido la existencia de otras formas de deformación artificial del cráneo en el centro del área de Tiwanaku (Blom et al., 1998).

La llegada de los incas estableció el tipo de deformación que correspondía al territorio circundante a San Pedro de Atacama, ya que cada provincia incaica tenía su propia forma de deformación de la cabeza (Borja Villanueva \& Gálvez Calla; Torres-Rouff, 2007).

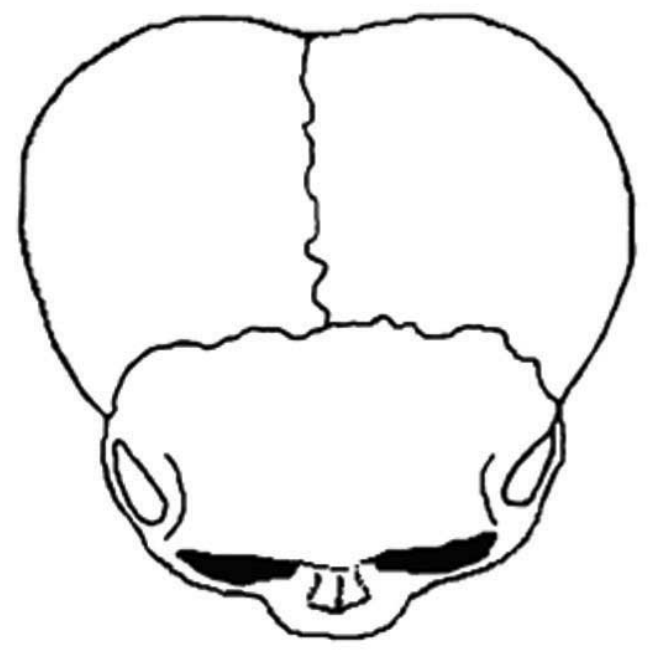

TABULAR (MODELA CRÁNEOS BRAQUICEFÁLICOS)

\section{MATERIAL Y MÉTODO}

La muestra consistió en 77 cráneos de atacameños prehispánicos de ambos sexos, del período post-Tiwanaku, que fueron elegidos al azar de un total de 293 individuos exhumados del cementerio Coyo Oriente, datados entre 3001200 d.C. y que forman parte del Museo R.P. Gustavo Le Paige en San Pedro de Atacama, dependiente del Instituto de Investigaciones Arqueológicas de la Universidad Católica del Norte. A los restos óseos no se les realizó ningún tipo de intervención o consolidación por ser patrimonio cultural de la nación, estando sólo autorizado el análisis y la observación de los cráneos, razón por lo cual fueron íntegramente fotografiados en todas sus normas anatómicas. También se mensuraron la longitud anteroposterior máxima del cráneo y la anchura máxima de cráneo con la finalidad de determinar el índice craneano o craneal.

En el mismo sentido se analizaron siete cráneos considerados aymaras, llamados así por el lenguaje que era hablado en el altiplano influenciado por el antiguo estado de Tiwanaku, desenterrados en las cercanías del oasis de Pica y pertenecientes al museo anatómico de la Universidad de Antofagasta, también fueron fotografiados y mensurados para determinar el índice craneano.

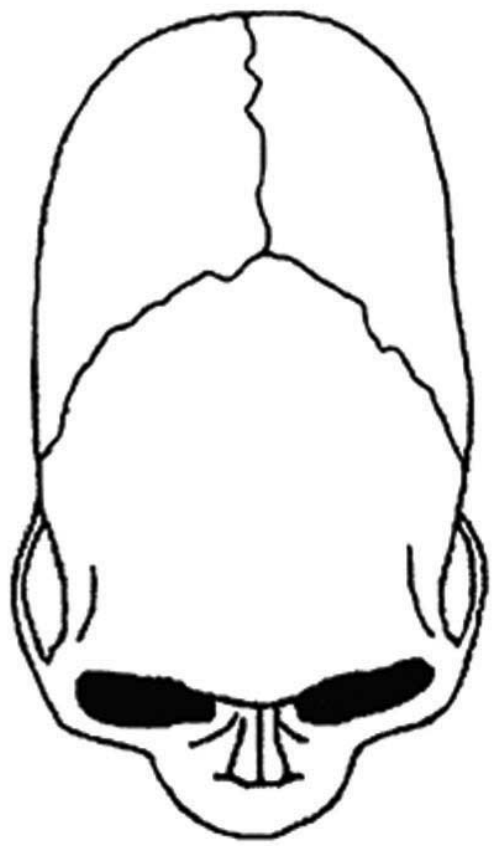

ANULAR O CIRCULAR (MODELA CRÁNEOS DOLICOCEFÁLICOS)

Fig. 1. Tipos más comunes de deformación craneana según método de presión (modificado de Torres-Rouff, 2007). 
Los datos obtenidos fueron vertidos a una planilla electrónica de Microsoft Excel para su tabulación y para el estudio estadístico se utilizó el programa Statgraphics Plus 5.1

\section{RESULTADOS}

Los resultados de los análisis estadísticos en cráneos atacameños y aymaras normales y deformados artificialmente se muestran en las Tablas I, II y III.

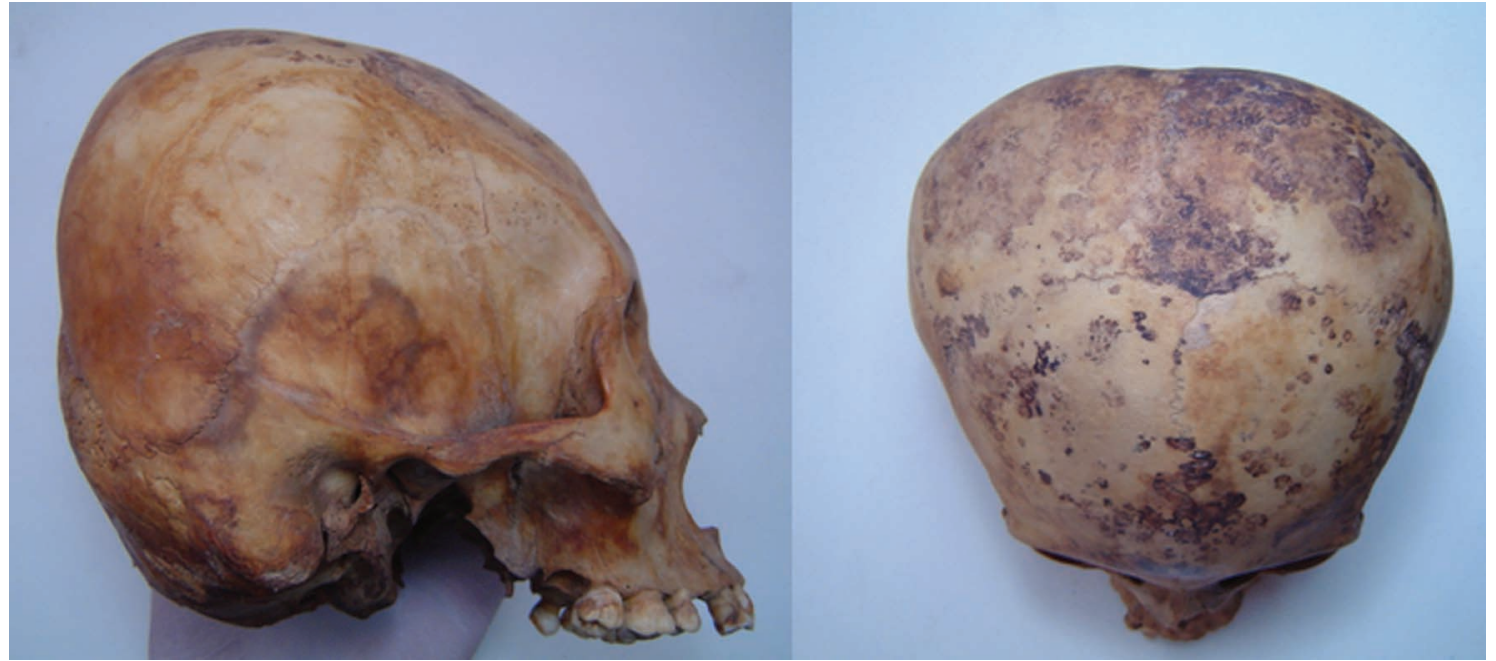

Fig. 2. Cráneos atacameños. Visión en normas lateral y superior. Deformación tabular.

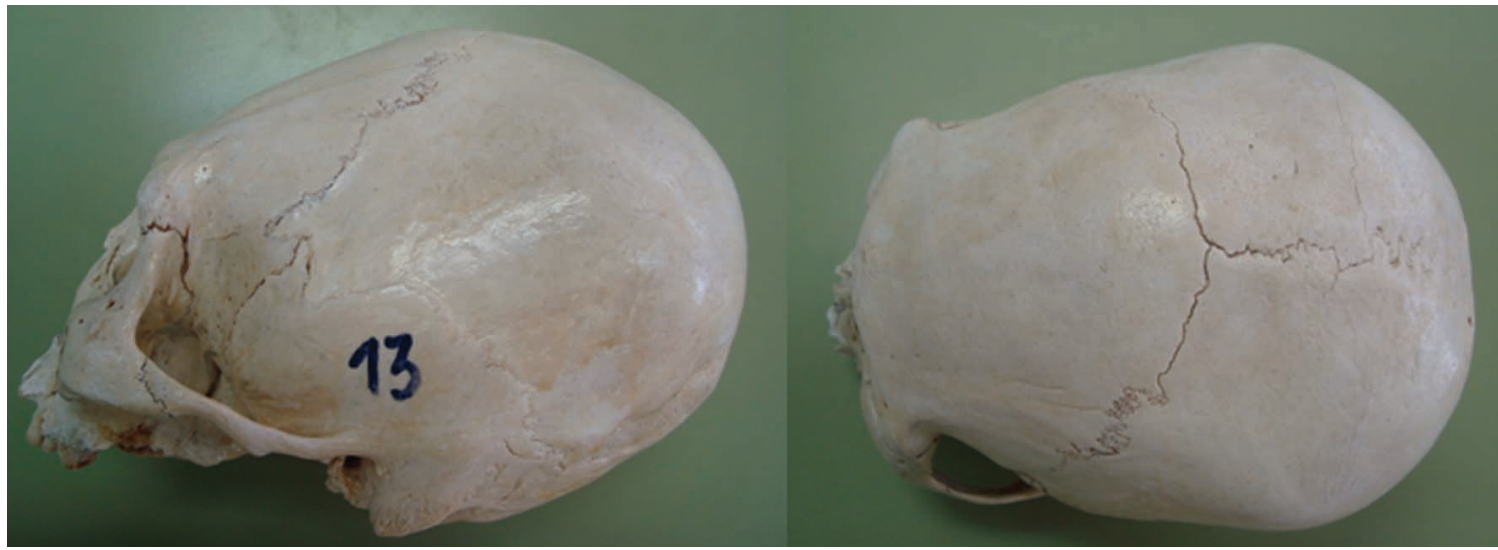

Fig. 3. Cráneos aymaras. Visión en normas lateral y superior. Deformación anular o circular.

Tabla I. Promedios Indice craneano en muestras de cráneos atacameños $(n=77)$ y aymaras $(n=7)$

\begin{tabular}{lcccc}
\hline GRUPO EN ESTUDIO & $\mathrm{n}$ & Promedio & DS & rango \\
\hline Atacameños (toda la muestra) & 77 & 87,84 & 7,72 & $77,33-117,24$ \\
Atacameños cráneo deformado & 27 & $92,63 * * *$ & 9,72 & $80,34-117,24$ \\
Atacameños cráneo no deformado & 50 & $85,25^{*}$ & 4,77 & $77,33-95,45$ \\
Aymara (todos cráneos deformados) & 7 & $76,00^{* *}$ & 6,66 & $64,17-83,02$
\end{tabular}

$* \mathrm{p}<0,5=0,0000266496$. Diferencia estadística significativa al 95\% del índice craneano entre cráneos atacameños deformados y no deformados.

$* * \mathrm{p}<0,05=0,00017227$. Diferencia estadística significativa al 95\% del índice craneano entre cráneos atacameños deformados y aymaras 
GARCÍA-HERNÁNDEZ, F \& MURPHY-ECHEVERRÍA, G. Índice craneano en grupos étnicos precolombinos del Norte de Chile con deformación craneal artificial Int. J. Morphol., 27(2):587-594, 2009.

Tabla II. Distribución porcentual grupos clasificatorios de índice craneano (atacameños n=77; aymaras=7)

\begin{tabular}{|c|c|c|c|c|c|c|c|c|c|c|c|}
\hline GRUPO EN ESTUDIO & $\mathrm{n}$ & HD & $\%$ & $\mathrm{D}$ & $\%$ & M & $\%$ & B & $\%$ & $\mathrm{HB}$ & $\%$ \\
\hline Atacameños (toda la muestra) & 77 & --- & --- & --- & --- & $6 / 50$ & 7.8 & $27 / 77$ & 35,1 & $44 / 77$ & 57,1 \\
\hline A tacameños cráneo deformado & 27 & --- & --- & --- & --- & --- & --- & $6 / 27$ & 22,2 & $21 / 27$ & $77,8 *$ \\
\hline Atacameños cráneo no deformado & 50 & --- & --- & --- & --- & $6 / 50$ & 12,0 & $21 / 50$ & 42,0 & $23 / 50$ & $46,0 *$ \\
\hline $\begin{array}{l}\text { Aymara (todos cráneos } \\
\text { deformados) }\end{array}$ & 7 & $1 / 7$ & 14,2 & $2 / 7$ & 28,6 & $2 / 7$ & 28,6 & $2 / 7$ & 28,6 & --- & --- \\
\hline
\end{tabular}

Tabla III. Porcentaje de cráneos deformados y método de deformación en muestras de atacameños (n=77) y aymaras (n=7).

\begin{tabular}{lcclc}
\hline Grupo & Cráneos deformados & $\%$ & Tipo de deformación & $\%$ \\
\hline Atacameños & $27 / 77$ & 35,1 & Tabular erecta 25/27 & 92,6 \\
& & & Circular o anular 2/27 & $7,4^{*}$ \\
Aymaras & $7 / 7$ & 100,0 & Circular o anular 7/7 & 100,0 \\
\hline
\end{tabular}

\section{DISCUSIÓN}

Es indudable que la deformación craneana artificial fue un procedimiento ritual en la mayoría de los pueblos originarios del continente americano, en especial de los grupos que habitaron el altiplano andino y los Andes centrales del sur.

En este contexto, la muestra atacameña en estudio presenta un $35,1 \%$ de cráneos deformados (Tabla III), valores similares a los registrados cuando se estudia la deformación craneana en San Pedro de Atacama, desde el período intermedio temprano hasta el horizonte tardío. Antecedentes aportados por Torres-Rouff (2007) señalan que, en etapas tempranas del poblamiento de San Pedro de Atacama, existe un $45 \%$ de cráneos que presentan deformación con fuerte porcentaje del método tabular erecto $(79,5 \%$ de los cráneos deformados), aumentando los cráneos con deformación a medida que se avanza en el tiempo, de tal modo que en el período intermedio tardío (circa 1.000 d. C.) el 66,2\% de los cráneos presentan algún tipo de deformación artificial con un alto porcentaje de deformación tabular erecto $(85,1 \%)$. Por último, durante el período horizonte tardío en San Pedro de Atacama, de fuerte influencia incaica, hay un alto valor porcentual de cráneos deformados y del tipo tabu$\operatorname{lar}(84,2 \%)$.

Por otro lado, nuestros resultados muestran diferencias estadísticamente significativas al $95 \%$ respecto de los datos aportados por otros investigadores que han investigado sobre deformación craneal en San Pedro de Atacama tales como Munizaga (1969) quien señala que el 79,6\% de los cráneos de la Fase Tardía en San Pedro de Atacama mostraban algún tipo de deformación, Costa-Junqueira (1988) que determina un $58,8 \%$ de deformación y Cocilovo et al. (1999) que establecen la existencia de un $58 \%$ de deformación craneal.
En el grupo atacameño el promedio del índice craneano determinado en cráneos deformados es de 92,63 SD 9,72, lo que clasifica a la muestra como francamente braquicefálica, con diferencia estadística significativa al 95\% respecto de cráneos no deformados (Tabla I). Al comparar los porcentajes de hiperbraquicefalia (Tabla II) entre individuos con cráneos deformados y no deformados $(77,8 \%$ $46,0 \%)$ se determina una diferencia estadística significativa al $95 \%(\mathrm{p}<0,05=0,00713022)$.

Cuando se analiza el porcentaje de braquicefalia, nuestra investigación arroja un $92,2 \%$ de cráneos braquicefálicos en la muestra de atacameños (Tabla III.), sin diferencias estadísticas significativas al $95 \%$ respecto de Le Paige (1961) que determina un $83 \%$ de braquicefalia en Fase Media de San Pedro de Atacama y de Costa-Junqueira que obtiene un $90 \%$ de braquicefalia en Quitor-6.

En San Pedro de Atacama entre el 40-60\% de los cráneos tienen deformación craneana artificial y en su mayoría corresponden a deformaciones de tipo tabular, antecedente similar al obtenido en nuestra investigación (92,6\% de los cráneos atacameños analizados y que poseen deformación craneana artificial, presentan deformación producida por el método tabular).

Lo anterior se ve ratificado al analizar la investigación de Torres-Rouff (2007), quien al revisar 605 cráneos asociados a diferentes enterramientos en San Pedro de Atacama, determina que 323 de 368 cráneos presentan deformación tabular, lo que representa el 87,8\% de los cráneos deformados, mientras que solamente 45/368 de los cráneos se han deformado mediante el método anular o circular lo que equivale al 12,2\%, ambos datos sin diferencia estadísti- 
ca significativa al $95 \%$ respecto de los resultados obtenidos en nuestra investigación (Tabla III), donde el 92,6\% de los cráneos están deformados artificialmente por el método tabular (cráneo braquicéfalo) y solo un 7,4\% habían sido deformados por el método anular o circular (cráneo dolicocéfalo).

Los siete cráneos aymaras, presentan deformación anular o circular con marcada tendencia a la dolicocefalia, como se aprecia en la Tabla II, donde un 42,8\% de los casos son dolicocéfalos o hiperdolicocéfalos.

En la zona costera de Arica, en el llamado grupo Chinchorro, se observó que el tipo anular era el único tipo de de deformación presente (Rothhammer \& Llop), apareciendo, en períodos tardíos y en diversos cementerios, la presencia de deformación tabular oblicua lo que supone contactos con otras poblaciones altiplánicas que utilizaba de forma preferente dicho modelo deformativo. Cocilovo et al. señalan que en Pisagua (entre 330-1450 d.C.) predominan cráneos deformados según modelo tabular producto de las relaciones con otros grupos próximos del norte de Chile y del área andina.

En San Pedro de Atacama durante el período intermedio temprano, los cráneos deformados que predominan corresponden al tabular $(35 / 4479,5 \%)$ y es a partir del período horizonte medio, que está fuertemente influenciado por la cultura Tiwanaku, donde se incrementan los casos de modelos de deformación anular o circular (14/52 con 27\%). Durante el período intermedio tardío (circa 1.000 d.C.) disminuyen marcadamente los cráneos con deformación anular o circular (22/268 con 8,2\%), en tanto durante el período horizonte tardío, producto de la influencia Incaica, encontramos un $84,2 \%$ de los cráneos deformados artificialmente mediante el método tabular (Torres-Rouff, 2007).

En Caspana, localidad ubicada al norte de San Pedro de Atacama y de fuerte influencia Tiawanacota Schiapacasse et al. indican que el método circular fue el utilizado en el 98,3\% de los cráneos deformados. Knudson \& Torres-Rouff (2009), se plantearon la hipótesis de que la población de Caspana (circa 1.100-1.400 d.C,) representaba a un grupo migratorio, para lo cual realizaron análisis de isótopos de estroncio y oxígeno, comprobando que un solo individuo de los 66 cráneos era originario de otro lugar y los 65 individuos restantes eran habitantes del poblado, con una alta frecuencia de de deformación craneal $(92,4 \%, n=61 / 65)$ predominando deformación anular o circular $(75,4 \%, \mathrm{n}=46 / 61)$. Lo anterior corrobora la presencia de grupos del norte de Chile, como los cráneos aymaras de Pica, individuos que influenciados por la cultura Tiawanacota, modificaron o adoptaron su método deformativo craneano al tipo circular predominante en el Estado Tiawanaku.

\section{CONCLUSIONES}

En los cráneos precolombinos del norte de Chile se observan deformaciones craneanas artificiales de los tipos tabular y anular o circular, las cuales fueron producidas mediante compresión craneal usando vendajes y tablas y realizadas durante los primeros años de vida de los individuos producto de la maleabilidad de los huesos del cráneo.

En el grupo atacameño destaca la deformación tabular lo que conlleva un predominio de la braquicefalia, con un promedio de índice craneano $=92,63$ y $\mathrm{SD}=9,72$, con diferencia estadística al $95 \%$ en relación al promedio del índice obtenido en cráneos no deformados $(\mathrm{p}<0,05=$ 0,0000266496; 100\% de braquicefalia en los cráneos deformados).

En los cráneos de individuos considerados aymaras, la deformación anular o circular es la única observada con una marcada tendencia a la dolicocefalia (promedio de índice craneano $=76,0$ y $\mathrm{SD}=6,66 ; 42,8 \%$ de casos con dolicocefalia).

Entre los promedios de índice craneano obtenidos para ambos grupos se determinó una diferencia estadística significativa al $95 \%(\mathrm{p}<0,05=0,00017227)$. En muchas poblaciones del norte de Chile, influenciadas durante siglos por la cultura transmitida por el Estado Tiawanaku, predominaba la deformación craneana circular característica de los tiawanacotas. Sin embargo, lo anterior no fue impedimento para que en otras comunidades de la región, sin lugar a dudas dependientes económica, comercial e incluso políticamente del poderoso estado, se realizaran principalmente deformaciones de tipo tabular. No existe un modelo de bóveda craneal deformada, con dolico o braquicefalia, que haya predominado en forma única, temporal y territorialmente en el norte de Chile.

\section{AGRADECIMIENTOS}

Los autores agradecen al Prof. Dr. Mark Hubbe, Director del Instituto de Investigaciones Arqueológicas y $\mathrm{Mu}$ seo R.P. Gustavo Le Paige en San Pedro de Atacama dependiente de la Universidad Católica del Norte, Chile, por su aporte y colaboración para la revisión del material antropológico atacameño utilizado en la presente investigación. Del mismo modo, agradecen el apoyo y colaboración del Señor Juan Godoy Núñez, Técnico de Laboratorio de la Unidad de Anatomía del Departamento Biomédico de la Universidad de Antofagasta, en la recolección de datos en los cráneos deformados de aymaras. 
GARCÍA-HERNÁNDEZ, F \& MURPHY-ECHEVERRÍA, G. Cranial index in precolumbian ethnic groups of Northern Chile with artificial cranial deformation. Int. J. Morphol., 27(2):587-594, 2009.

SUMMARY: During the period pre-Columbian in Northern Chile inhabited various groups, with notorious ethno-cultural differences. One of its characteristics was the artificial craneal deformation using bandages or boards from the first years of age, existing two big models of deformation: tabular that produces brachicephally and annular or circular that determinates dolicocephally. The investigation is to determine the relationship between habitat, type of artificial deformation, and shape of the head determined by the cranial index. We analyzed 77 atacameños skulls of both sexes, selected at random between 293 individuals of the Coyo-Orient cementery, dated between 300-1200 A.C. post-Tiwanaku period. These remains are part of R.P. Gustavo Le Paige`s Museum in San Pedro de Atacama, wich is part of the Institute of Archaeological Investigations of the North Catholic University. In addition, we analyzed seven aymaras skulls with artificial cranial deformation belonging to the anatomical museum of the University of Antofagasta. All skulls were analyzed, photographed in all anatomical norms and measured to obtain the cranial index. We comprobated that $35.1 \%$ of atacameños skulls were artificially deformed with prevalence of tabular deformation (92.6\%). The deformed skulls presented a cranial index average of 92.63 , SD 9.72 and $100 \%$ of brachicephalic cases. The seven aymaras skulls were deformed by annular or circular method, with an average of craneal index of 76.0, SD 6.66 and $42.8 \%$ of dolicocephalic cases. Statistical analisis showed significant differences at $95 \%$ level of craneal index between atacameños with deformed skulls and aymaras, and likewise, between atacameños with deformed and undeformed skulls. In the Northern Chile, the artificial deformed skulls can embrace brachicephalic or dolicocephalic form, without predominance at territorial, epoch or cultural cause.

KEY WORDS: Cranial index; Artificial cranial deformation; Northern Chile.

\section{REFERENCIAS BIBLIOGRÁFICAS}

Aldunate, C.; Berenguer, J.; Castro, V.; Cornejo, L.; Martínez, J. L. \& Sinclaire, C. Sobre la cronología del Loa superior. Chungará (16-17):333-46, 1986.

Björk, A. \& Björk, L. Artificial deformation and cranio-facial asymmetry in ancient peruvians. J. Dent. Res., 43(3):353-62, 1964.

Blom, D. E; Hallgrimsson, B.; Keng, L.; Lozada, C. M. C. \& Buikstra, J. E. Tiwanaku 'Colonization': Bioarchaeological Implications for Migration in the Moquegua Valley, Peru. World Archaeol., 30:238-61, 1988.

Boada, A. M. La deformación craneana como marcador de diferenciación social. http://www.lablaa.org/blaavirtual/ publicaciones/banrep/bolmuseo/1995/endi3839/ endi07b.

Borja Villanueva, C. A. \& Gálvez Calla, L. H. Deformaciones cefálicas en el antiguo Perú. Odontol. Sanmarquina, 9(1):31-5, 2006.

Bustos, A. Etnografía Atacameña. $1^{\text {a }}$ ed. Antofagasta, Editorial Universidad de Antofagasta, 1999. pp.57-92.

Bustos, A. \& Lehnert, R. Historia del pueblo atacameño. $1^{\mathrm{a}}$ ed. Antofagasta, Fundación Minera Escondida, 2000.

Castro, V.; Aldunate, C. \& Berenguer, J. Orígenes altiplánicos de la fase Toconce. Estudios Atacameños, 7:209-35, 1984.

Comas, J. Manual de Antropología Física. $2^{\mathrm{a}}$ ed. Ciudad de México, Editorial UNAM, 1976.

Costa-Junqueira, M. A. Reconstitución física y cultural de la población tardía del cementerio Quitor-6 (San Pedro de Atacama). Estudios Atacameños, 9:99-126, 1988.

Cocilovo, J. A.; Quevedo, S.; Varela, H. H.; Valdano, S. \& Castro, M. Biología del grupo prehistórico de Piragua, costa Norte de Chile. Estudios Atacameños, 17:207-35, 1999.

Del Sol, M. Índice cefálico en un grupo de individuos mapuches de la IX Región de Chile. Int. J. Morphol., 23(3):241-46, 2005.

Knudson, K. J. La influencia de Tiwanaku en San Pedro de Atacama: Una investigación utilizando el análisis de isótopos del estroncio. Estudio Atacameños: Arqueología y Antropología Surandinas, 33:7-24, 2007.

Knudson, K. J.; Torres-Rouff, C. Investigating cultural heterogeneity in San Pedro de Atacama, Northern Chile, through biogeochemistry and bioarchaeology. Am. J. Phys. Antrhopol., 138:473-85, 2009.

Le Paige, G. Estudio craniométrico de la colección de crá- 
neos del Museo Arqueológico de San Pedro de Atacama. Anales de la Universidad del Norte, 1(1):27-110, 1961.

Martí, I. \& Rothhammer, F. Variación del índice craneano en Sudamérica: contribuciones cronológicas, altitudinales y climáticas. Chungará, 18:181-7, 1987.

Meskell, L. The irresistible body and the seductions of achaeology. Changing bodies, changing meanings: Studies on the human body in antiquity. D. Montserrat (Ed). Routledge, New York, 1998.

Morel, P. La Antropología Física. Buenos Aires, Editorial Universitaria de Buenos Aires, 1964.

Munizaga, J. Deformación craneana intencional en San Pedro de Atacama. Actas del V Congreso Nacional de Arqueología. La Serena, Museo Arqueológicos de La Serena, 1969.

Museo del Arte Pre-Colombino. Los primeros americanos y sus descendientes. Santiago de Chile, Editorial Antártica S.A., 1988.

Rothhammer, F. \& Llop, E. Poblaciones chilenas: cuatro décadas de investigaciones bioantropológicas. Santiago de Chile, Editorial Universitaria, 2004.

Schiapacasse, V.; Castro, V. \& Niemeyer, H. Los desarrollos regionales en el norte grande. En "Culturas de Chile. Prehistoria. Desde sus orígenes hasta los albores de la conquista. Hidalgo, J.; Schiapacasse, V.; Niemeyer, H.; Aldunate, C. \& Solimano, I. (Eds). Santiago de Chile, Editorial Andrés Bello, 1989. pp.181-220.

Shijman, E. Artificial craneal deformation in the precolumbian Andes. Childs Ner. Syst., 21:939, 2005.

Torres-Rouff, C. Shaping identity: Craneal vault modification in the pre-columbian Andes. Tesis Doctoral, University of California, Santa Barbara, 2003.

Torres-Rouff, C. \& Yablonsky, L. T. Craneal vault modification as an cultural artifact: a comparison on Eurasian steppes an the Andes. Homo, 56(1):1-16, 2005.

Torres-Rouff, C. La deformación craneana en San Pedro de Atacama. Estudios Atacameños: Arqueología y Antropología Surandinas, 33:25-38, 2007.

Valls, A. Introducción a la Antropología. Fundamentos de la evolución y de la variabilidad biológica del hombre. $2^{\mathrm{a}}$ ed. Barcelona, Editorial Labor S.A., 1985.
Dirección para correspondencia:

Dr. Fernando García-Hernández

Unidad de Anatomía

Departamento Biomédico

Facultad de Ciencias de la Salud

Universidad de Antofagasta

Antofagasta, CHILE

Coquimbo 945 Depto. 64

Antofagasta - CHILE

Email: fgarcia@uantof.cl

Recibido : 18-01-2009

Aceptado: 25-02-2009 